\title{
Evaluation of Clinical Performance of Cast Metal vs. Glass Fiber Posts in the Restoration of Endodontically Treated Teeth
}

\author{
Mohit Bhatnagar ${ }^{1}$, Leena Tomer ${ }^{2}$, Pramiti Saxena ${ }^{3}$, Arti Singh ${ }^{4}$, Veenuka Sharma ${ }^{5}$, Satvik Singh ${ }^{6}$ \\ 1, 2, 4, 5, 6 Department of Prosthodontics, Crown and Bridge, Divya Jyoti College of Dental \\ Sciences and Research, Modinagar, Uttar Pradesh, India. ${ }^{3}$ Department of ITS Dental \\ College, Hospital and Research Centre, Greater Noida, Uttar Pradesh, India.
}

\section{ABSTRACT}

\section{BACKGROUND}

Endodontically treated teeth are usually associated with insufficient coronal and radicular tooth structure and hence, are restored with both cast metal and fiber posts. However, there are limitations in both treatment options. Glass fiber posts have known to show better performance than cast metal posts due to similarity in elastic modulus with dentin. The purpose of this study was to compare and evaluate the performance of glass fiber and cast metal posts in endodontically treated teeth that required intraradicular retention.

\section{METHODS}

40 endodontically treated teeth were selected in patients and divided into two groups, glass fiber, and cast metal respectively. The participants were randomly allocated to both groups by using their registration number with an allocation ratio of 1:1. Participants were recalled at 3 and 6 months after cementation (baseline) for follow up. Radiographs were taken and evaluation was done according to FDI criteria. The intergroup comparison for the difference of mean scores between the two independent groups was done using the unpaired / independent $t$ test.

\section{RESULTS}

Of the 40 endodontically treated teeth, 20 were restored with fiber posts and 20 were restored with cast metal posts. In total, 8 incisors, 6 canines, 21 premolars, and 5 molar teeth were included. The 6-month clinical survival of fiber posts was $100 \%$ while that of cast metal posts was $95 \%$. The results were found to be nonsignificant $(\mathrm{P}=0.159,0.231,0.805$ at baseline, 3 months, and 6 months respectively).

\section{CONCLUSIONS}

The overall performance of the glass fiber posts was better than that of cast metal posts within the 6 months' study period. However, no statistically significant differences were seen. Hence, in short follow up periods, both showed similar results and performed equally well.

\section{KEY WORDS}

Glass Fiber Posts Cast Metal Post Post and Core Technique Endodontically Treated Teeth

\begin{abstract}
Corresponding Author: Dr. Mohit Bhatnagar, H 37, Sector 22, Noida, Gautam Buddha Nagar - 201301, Uttar Pradesh, India.

E-mail: drmohitbhatnagar93@gmail.com

DOI: $10.14260 /$ jemds $/ 2021 / 313$

How to Cite This Article:

Bhatnagar M, Tomer L, Saxena $P$, et al. Evaluation of clinical performance of cast metal vs. glass fiber posts in the restoration of endodontically treated teeth. J Evolution Med Dent Sci 2021;10(20): 1496-1500, DOI:

$10.14260 /$ jemds $/ 2021 / 313$
\end{abstract}

Submission 31-12-2020,

Peer Review 10-03-2021,

Acceptance 16-03-2021,

Published 17-05-2021.

Copyright (C) 2021 Mohit Bhatnagar et al. This is an open access article distributed under Creative Commons Attribution License [Attribution 4.0 International (CC BY 4.0)] 


\section{BACKGROUND}

Endodontically treated teeth are usually associated with insufficient coronal and radicular tooth structure due to various reasons including dental caries, trauma, endodontic access preparation, etc. ${ }^{1}$ The success of post endodontic restorations is highly dependent on the amount of residual coronal dentin. Moreover, it is necessary to preserve at least one coronal wall to successfully restore a root canal treated tooth. In such a situation, gaining support by insertion of a rigid post into the root canal of an endodontically treated tooth, allows the prosthetic core to be constructed and the final prosthesis to be retained. ${ }^{2}$

Posts are generally categorised as custom fabricated and prefabricated. Materials used for prefabricated posts have been metal alloys in the form of stainless steel, titanium alloys, gold plated brass and other materials such as ceramic and fiber reinforced polymers. Custom fabricated cast gold post and core and other base metal alloys have also been used since a long time to restore teeth with excessive loss of structure. ${ }^{1}$

Cast metal posts have been the majorly used method of intraradicular retention since a long time. Owing to the high modulus of elasticity in comparison with that of human dentine, metal posts increase stress concentration in the luting cement, leading to its failure with an added chance of root fracture as well. ${ }^{2}$ The impact of lateral forces also causes vibration and debonding as a result of rigidity in these posts. The focusing of these forces in unpredictable "critical points" along with a tendency for metal corrosion can eventually lead to failure of the prosthesis. ${ }^{3}$ The stress concentration over a smaller area is another cause of root fracture. ${ }^{4}$ This has led to a dire need for search of a material that has a favourable modulus of elasticity mimicking dentin. ${ }^{3}$

Hence, a uniformity in stress distribution leads to a significant reduction in interfacial stress and chances of failure. This phenomenon has been coined "monobloc.", a characteristic of fiber posts. ${ }^{5}$

Fiber posts came into practice in the early 1990s, and provided an efficient means to restore the teeth ahead of cast alloy-based posts and cores, as well as metal and ceramic posts. ${ }^{6}$ Fiber-reinforced posts bond with most luting agents like resin and composite core materials. A better bond is known to reduce the wedging effect of the post. Moreover, there is a minimal tendency of fracture owing to reduced dentinal trimming since a shorter and thinner post can also be used. The significance of shape in case of fiber-reinforced posts may also be negated in comparison with a metal post (parallel versus tapered). Fiber-reinforced posts are free of metal allergies or corrosion effects as they are metal-free. ${ }^{7}$ In addition, optical transillumination offers light activation of photopolymerizable adhesive materials within the canal. Moreover, they offer better aesthetics beneath all ceramic restorations due to the translucency. ${ }^{8}$

However, it was found out that the low elastic modulus of certain fiber post brands is responsible for debonding at the restoration interface even though they do not lead to fractures. ${ }^{9}$ With post debonding being the major cause of failure, the other causes include secondary caries, and restorable cervical fractures. ${ }^{10}$

Various fiber posts are made of highly cross-linked epoxy resin that is believed to cause difficulties in bonding with methacrylate-based resin cements. ${ }^{11}$ Water sorption resulting from prolonged storage can also lead to change in physical properties like flexural strength and elastic modulus (leading to expansion), dynamic functional loading, and changes in temperature. 12

Hence, the purpose of this study was to compare and evaluate the performance of glass fiber and cast metal posts in endodontically treated teeth that required intraradicular retention. The hypothesis proposed that the clinical outcome of endodontically treated teeth would not differ according to the type of post used.

\section{METHODS}

This prospective, parallel group randomised clinical trial was conducted in the Department of Prosthodontics, Crown and Bridge from April 2018 to April 2019. Sample size was calculated with \pm 0.5 of standard deviation with a minimum expected difference of 0.52 and 0.05 of significance at $90 \%$ statistical power. A total of 40 endodontically treated teeth were selected in 32 patients irrespective of their socioeconomic status, religion, age and sex and divided into two groups, Glass Fiber posts, and Cast Metal posts respectively with follow up at 3 months and 6 months. The study was approved by the Institute's dental ethics committee (Ref No. DJD / IEC / 2018 / A - 24). All possible treatment options were thoroughly discussed with the patients and a written consent from the patients was taken.

\section{Inclusion Criteria}

1. Presence of one or more endodontically treated anterior or posterior teeth (ferrule height $>1 \mathrm{~mm}$ ) requiring intraradicular retention

2. Teeth with complete root formation

3. No sinus / periapical pathology

\section{Exclusion Criteria}

1. Untreated periodontitis (pocket depth $>3 \mathrm{~mm}$ )

2. Patients with serious medical conditions whereby a normal treatment and follow up couldn't be guaranteed

3. Patients with known allergies to products that were planned to be used in the study.

Clinical and radiographic examination of each tooth was carried out prior to canal preparation, for decision making in order to proceed for post placement. The participants were randomly allocated to both groups based on previously generated random number sequence (block random sample design) with an allocation ratio of 1:1. Allocation to the groups was done by a person who was independent of the research, so as to prevent bias.

For teeth restored with glass fiber posts (Figure 1, 2), an appropriate size of glass fiber post (RelyX, 3M ESPE) was selected for each canal on the basis of preoperative radiographs and clinical judgement. Then, Canal preparation was carried out with peeso reamer (Mani, Japan), removing 2 / 3 of the gutta - percha filling in the canals. 

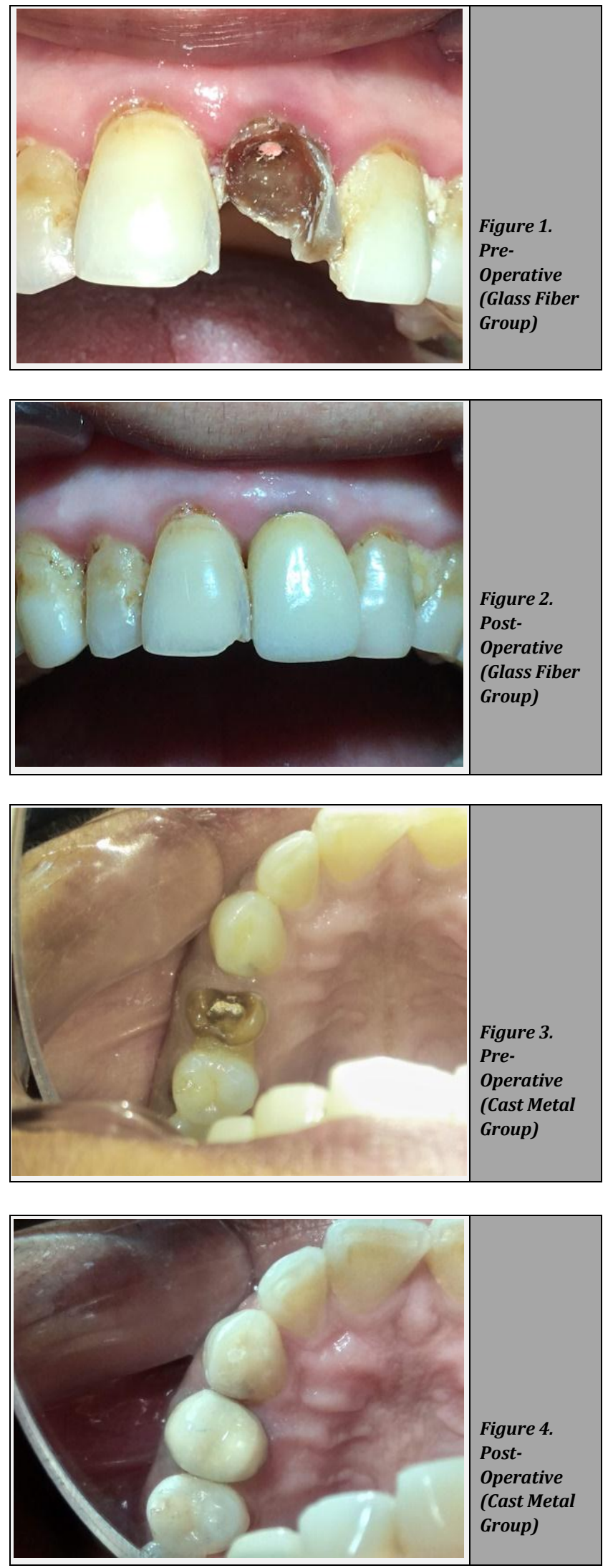

Canals were then prepared with the drills compatible with the fiber post system (RelyX, 3M ESPE). Post alignment was analysed using a periapical radiograph. The canals were cleaned with sodium hypochlorite solution (Vishal Dentocare Pvt Ltd), rinsed off with normal saline (Cipla) and dried with paper points (Dentsply Maillefer). The post was luted with self-adhesive resin cement (RelyX U200; 3M ESPE). Digital pressure was applied for 30 seconds, curing light was shown for 20 seconds and excess cement was removed. A core of resin modified glass ionomer cement (Vitremer, 3M ESPE) was built over the post and followed by tooth preparation for porcelain fused to metal (PFM) crown.

For teeth restored with cast metal posts (Figure 1, 2)), post space was prepared in the same manner as in Group 1. Cast metal post $(\mathrm{Ni}-\mathrm{Cr}$ ) and core impression was made directly with pattern resin (GC). After it was casted and tried in the tooth, the custom-made post and core was then cemented in the tooth with self-adhesive resin cement (RelyX U200; 3M ESPE). An impression (Zetaplus, Zhermack) of the prepared tooth was made while that of the opposing arch made in irreversible hydrocolloid (Tropicalgin, Zhermack). The PFM crown was cemented in place after fabrication with glass ionomer cement (GC Gold label 1, GC America Inc.) Baseline clinical parameters and radiographs were recorded. These were also repeated at 3 months and 6 months' interval.

Clinical and radiographic examinations were carried out 3 and 6 months after cementation (baseline). Periapical radiographs were taken, and evaluation was done according to Federation Dentaire International (FDI) Criteria. ${ }^{13}$ Scoring was done from 1 to 5 on certain Functional Criteria (Fracture of restorative material and restoration retention, Radiographic examination, Patient satisfaction with restoration; and Biologic Criteria (Recurrence of initial pathology, Effect of the restoration on the periodontium). Score 1 when the quality of the restoration was excellent. Score 2 indicated highly acceptable restoration, although one or more criteria deviated from score 1 . Score 3 meant sufficiently acceptable but with minor shortcomings. Score 4 was unacceptable but repairable, whereas a score 5 had to be replaced.

\section{Statistical Analysis}

The data for the present study was analysed using the SPSS statistical software 19.0 Version (IBM Inc., Chicago, USA). The descriptive statistics included mean and standard deviation. The level of the significance for the present study was fixed at $5 \%$. The intergroup comparison for the difference of mean scores between two independent groups was done using the unpaired / independent t test.

\section{RESULTS}

40 root canal treated teeth in 32 patients were selected, wherein 20 each were treated with the cast metal posts and glass fiber posts including 8 incisors, 6 canines, 21 premolars, and 5 molar teeth.

None of the teeth had periodontal problems and no endodontic-related pain was reported. One failure was observed in the cast metal group and was identified to be debonding at post cement junction. The 6-month clinical survival of fiber posts was $100 \%$ while that of cast metal posts was $95 \%$.

At baseline the mean functional score for fiber and cast metal group was $1.60 \pm 0.598$ and $1.90 \pm 0.718$ respectively $(\mathrm{P}=0.159)$. The mean biological score for fiber and cast metal group was $1.0(\mathrm{P}=1.000)$. The overall score at baseline for fiber group and cast metal group was $1.60 \pm 0.598$ and $1.90 \pm$ 0.718 respectively $(\mathrm{P}=0.159)$. 


\begin{tabular}{|c|c|c|c|c|c|c|c|}
\hline \multirow[b]{2}{*}{ Criteria } & \multirow[t]{2}{*}{ Group } & \multicolumn{2}{|c|}{ Baseline } & \multicolumn{2}{|c|}{3 Months } & \multicolumn{2}{|c|}{6 months } \\
\hline & & $\begin{array}{l}\text { Mean } \\
\text { Score }\end{array}$ & $\begin{array}{c}P \\
\text { Value }\end{array}$ & $\begin{array}{l}\text { Mean } \\
\text { Score }\end{array}$ & $\begin{array}{c}P \\
\text { Value }\end{array}$ & $\begin{array}{l}\text { Mean } \\
\text { Score }\end{array}$ & $\begin{array}{c}P \\
\text { Value }\end{array}$ \\
\hline \multirow[b]{2}{*}{ Functional } & Fiber & $1.60 \pm 0.598$ & \multirow{2}{*}{0.159} & $1.75 \pm 0.638$ & \multirow{2}{*}{0.012} & $2.25 \pm 0.550$ & \multirow{2}{*}{$\begin{array}{ll}0 & \\
1 & 0.819\end{array}$} \\
\hline & $\begin{array}{c}\text { Cast } \\
\text { metal }\end{array}$ & $1.90 \pm 0.718$ & & $2.25 \pm 0.550$ & & $2.30 \pm 0.801$ & \\
\hline \multirow[b]{2}{*}{ Biological } & Fiber & 1.00 & \multirow{2}{*}{1.000} & $2.00 \pm 0.648$ & \multirow{2}{*}{0.324} & $2.45 \pm 0.510$ & \multirow{2}{*}{$\begin{array}{l}0.735 \\
9\end{array}$} \\
\hline & $\begin{array}{c}\text { Cast } \\
\text { metal }\end{array}$ & 1.00 & & $2.20 \pm 0.615$ & & $2.35 \pm 0.489$ & \\
\hline \multirow[b]{2}{*}{$\begin{array}{l}\text { Overall } \\
\text { score }\end{array}$} & Fiber & $1.60 \pm 0.598$ & \multirow{2}{*}{0.159} & $2.25 \pm 0.550$ & \multirow{2}{*}{0.231} & $2.65 \pm 0.489$ & \multirow{2}{*}{${ }_{3}^{9} 0.805$} \\
\hline & $\begin{array}{l}\text { Cast } \\
\text { metal }\end{array}$ & $1.90 \pm 0.718$ & & $2.45 \pm 0.510$ & & $2.60 \pm 0.753$ & \\
\hline & Table 1 & 1. Inter Grou & up Com & parison of 1 & Functic & onal and & \\
\hline
\end{tabular}

After 3 months the mean functional score for fiber group and cast metal group was $1.75 \pm 0.638$ and $2.25 \pm 0.550$ respectively ( $\mathrm{P}=0.012$ ). The mean biological score for fiber group and cast metal group was $2.00 \pm 0.648$ and $2.20 \pm$ 0.615 respectively $(\mathrm{P}=0.324)$. The overall score after 3 months for fiber group and cast metal group was $2.25 \pm 0.550$ and $2.45 \pm 0.510$ respectively $(\mathrm{P}=0.231)$.

After 6 months the mean functional score for fiber group and cast metal group was $2.25 \pm 0.550$ and $2.30 \pm 0.801$ respectively $(\mathrm{P}=0.819)$. The mean biological score for fiber group and cast metal group was $2.45 \pm 0.510$ and $2.35 \pm$ 0.489 respectively $(P=0.735)$. The overall score after 6 months for fiber group and cast metal group was $2.65 \pm 0.489$ and $2.60 \pm 0.753$ respectively $(\mathrm{P}=0.805)$. The results were found to be non - significant.

\section{DISCUSSION}

Post debonding, fractures, radiographic changes and overall survival were analysed in glass fiber and cast metal post groups at baseline, 3 months, and 6 months, indicating that the overall clinical survival of both the groups was similar and the results were not significant.

In this study, 40 posts were cemented that included 20 each in both the groups. The clinical survival of fiber posts was $100 \%$ while that of cast metal posts was $95 \%$. Out of the 40 cases, 1 failure from group II (Cast Metal) was noted in the form of post debonding at post cement junction. This could be attributed to the fact that the elastic modulus mismatch, ${ }^{14} \mathrm{a}$ significant cause in itself could lead to debonding at the interface. Metal posts exhibit stiffness and the resistance to distortion under loading might have concentrated a greater magnitude of shear stress at the post cement interface.

This was in accordance with an in vitro study conducted by Ona et al. (2013),15 who concluded that the difference in elastic modulus among the tooth and post and core restoration could be an essential reason determining debonding of the restoration.

Verri et al. (2017) ${ }^{16}$ also found that the elastic modulus of the glass fiber posts was similar to that of dentin, resulting in a better stress distribution as compared to metal posts.

In this study, both groups were luted with self-adhesive resin cement, which was highly advantageous because of a relative ease of working and ability to with stand detrimental effects of moisture. Moreover, it does not require acid etching or an adhesive step. ${ }^{17,18,19,20}$
At baseline, the overall score in both the groups came below score 2 and hence the restorations were considered excellent. After 3 months and 6 months of follow up, the overall score in both the groups was below score 3 rendering the prostheses as highly acceptable. Considering the overall scores for both the groups, no statistically significant difference was found in the performance of both the groups. This was in accordance with a study ${ }^{2}$ by Onofre et al. wherein after 3 years of follow up, both glass fiber and cast metal posts, regardless of tooth location exhibited similar survival. A systematic review ${ }^{21}$ by Heydecke et al. compared the clinical and in vitro performance of cast metal and prefabricated posts and found that no particular post was superior. Cloet et al. ${ }^{7}$ in his 5 year follow-up also concluded that both glass fiber composite with cast post and cores performed equally well.

A study ${ }^{6}$ by Zicari et al. compared the clinical performance of cast metal and glass fiber posts and concluded that the success rate at 3 years came out to be 91.7 $\%$ in all groups. He stated that longer follow-up times were needed to detect possible significant differences. Piovesan et al. ${ }^{22}$ in his study found a survival rate of $90.2 \%$ for fiberreinforced custom posts after 97 months. Gomez-Polo et al. ${ }^{23}$ on the other hand reported a survival rate of $82.6 \%$ at 10 years for cast metal posts. $\mathrm{Ma} \mathrm{H}$ et al. ${ }^{24}$ in their study concluded that the abutment teeth, have a significant survival rate whether restored by glass fiber, cast metal, or without post. A systematic review by Marchionatti et al. ${ }^{25}$ analysed various studies that showed no difference in the performance of various fiber and metal posts.

A longer follow up period could possibly detect differences in performances between the two groups. A larger sample size would also prove to be a critical factor in determining a conclusive difference between the two groups.

\section{CONCLUSIONS}

In conclusion, after 6 months of follow up, both glass fiber and cast metal posts showed highly acceptable and similar survival rates.

- No significant differences were observed with respect to the fracture, radiographic changes, and periodontal changes. Hence, the null hypothesis wasn't rejected.

- The overall performance of the glass fiber post was better than that of cast metal post group after 6 months follow up but it was not statistically significant. A longer follow up of the restorations along with a larger sample size will be required for further assessment.

\section{Clinical Significance}

Endodontically treated teeth often present the need to be restored with both cast metal and fiber posts. However, there are limitations in both treatment options. Glass fiber posts have been known to show better performance than cast metal posts due to similarity in elastic modulus with dentin. However, in short follow up periods, both show similar results and perform equally well. Hence, selection of the better option should be based on a longer follow up time. 
Data sharing statement provided by the authors is available with the full text of this article at jemds.com.

Financial or other competing interests: None.

Disclosure forms provided by the authors are available with the full text of this article at jemds.com.

\section{REFERENCES}

[1] Uthappa R, Mod D, Kharod P, et al. Comparative evaluation of the metal post and fiber post in the restoration of the endodontically treated teeth. J Dent Res Rev 2015;2(2):73-7.

[2] Sarkis-Onofre R, De Castilho Jacinto R, Boscato N, et al. Cast metal vs. glass fibre posts: a randomized controlled trial with up to 3 years of follow up. J Dent 2014;42(5):582-7.

[3] Gbadebo OS, Ajayi DM, Oyekunle OOD, et al. Randomized clinical study comparing metallic and glass fiber post in restoration of endodontically treated teeth. Indian J Dent Res 2014;25(1):58-63.

[4] Garhnayak L, Parkash H, Sehgal D, et al. Different endodontic post-retained teeth with and without ferrule design- a finite element analysis. ISRN Dent 2011:2011:102329.

[5] Shashikala K, Sharma S. Clinical and radiological evaluation of cast metal and quartz fibre posts in endodontically restored teeth. Endodontology 2011;23(2):37-46.

[6] Zicari F, Meerbeek BV, Debels E, et al. An up to 3-year controlled clinical trial comparing the outcome of glass fiber posts and composite cores with gold alloy-based posts and cores for the restoration of endodontically treated teeth. Int J Prosthodont 2011;24(4);363-72.

[7] Cloet E, Debels E, Naert I. Controlled clinical trial on the outcome of glass fiber composite cores versus wrought posts and cast cores for the restoration of endodontically treated teeth: a 5 year follow up study. Int J Prosthodont 2017;30(1):71-9.

[8] Moraes AP, Cenci MS, De Moraes RR, et al. Current concepts on the use and adhesive bonding of glass-fiber posts in dentistry: a review. Applied Adhesion Science 2013;1:4.

[9] Parisi C, Valandro LF, Ciocca L, et al. Clinical outcomes and success rates of quartz fiber post restorations: a retrospective study. J Prosthet Dent 2015;114(3):36772.

[10] Guldener KA, Lanzrein CL, Guldener BES, et al. Long-term clinical outcomes of endodontically treated teeth restored with or without fiber post-retained single-unit restorations. J Endod 2017;43(2):188-93.

[11] Onofre RS, Fergusson D, Cenci MS, et al. Performance of post-retained single crowns: a systematic review of related risk factors. J Endod 2017;43(2):175-83.
[12] Figueiredo FED, Martins-Filho PRS, Faria-E-Silva AL. Do metal post-retained restorations result in more root fractures than fiber post-retained restorations? A systematic review and meta-analysis. J Endod 2015;41(3):309-16.

[13] Marquiller T, Domejean S, Le Clerc J, et al. The use of FDI criteria in clinical trials on direct dental restorations: a scoping review. J Dent 2018;68:1-9.

[14] Muttlib NAA, Azman ANP, Seng YT, et al. Intracanal adaptation of a fiber reinforced post system as compared to a cast post-and-core. Acta Stomatol Croat 2016;50(4):329-36.

[15] Ona M, Wakabayashi N, Yamazaki T, et al. The influence of elastic modulus mismatch between tooth and post and core restorations on root fracture. Int Endod J 2013;46(1):47-52.

[16] Verri FR, Okumura MHT, Lemos CAA, et al. Threedimensional finite element analysis of glass fiber and cast metal posts with different alloys for reconstruction of teeth without ferrule. J Med Eng Technol 2017;41(8):644-51.

[17] Mohajerfar M, Nadizadeh K, Hooshmand T, et al. Coronal microleakage of teeth restored with cast posts and cores cemented with four different luting agents after thermocycling. J Prosthodont 2019;28(1):e332-6.

[18] Pedreira AP, D'Alpino PH, Pereira PN, et al. Effects of the application techniques of self-adhesive resin cements on the interfacial integrity and bond strength of fiber posts to dentin. J Appl Oral Sci 2016;24(5):437-46.

[19] Pereira JR, Do Valle AL, Ghizoni JS, et al. Push-out bond strengths of different dental cements used to cement glass fiber posts. J Prosthet Dent 2013;110(2):134-40.

[20] Soares CJ, Pereira JC, Valdivia AD, et al. Influence of resin cement and post configuration on bond strength to root dentine. Int Endod J 2012;45(2):136-45.

[21] Heydecke G, Peters MC. The restoration of endodontically treated, single-rooted teeth with cast or direct posts and cores: a systematic review. J Prosthet Dent 2002;87(4):380-6.

[22] Piovesan EM, Demarco FF, Cenci MS, et al. Survival rates of endodontically treated teeth restored with fiberreinforced custom posts and cores: a 97-month study. Int J Prosthodont 2007;20(6):633-9.

[23] Gómez-Polo M, Llidó B, Rivero A, et al. A 10-year retrospective study of the survival rate of teeth restored with metal prefabricated posts versus cast metal posts and cores. J Dent 2010;38(11):916-20.

[24] Ma H, Shen L, Liu K, et al. Cinical evaluation of residual crowns and roots restored by glass fiber post and core, cast metal post and core or directly. Hua Xi Kou Qiang Yi Xue Za Zhi 2013;31(1):45-8.

[25] Marchionatti AME, Wandscher VF, Rippe MP, et al. Clinical performance and failure modes of pulpless teeth restored with posts: a systematic review. Braz Oral Res 2017;31:e64. 